\title{
The $\beta$-globin locus control region (LCR) functions primarily by enhancing the transition from transcription initiation to elongation
}

\author{
Tomoyuki Sawado, ${ }^{1}$ Jessica Halow, ${ }^{1}$ M.A. Bender, ${ }^{2,3}$ and Mark Groudine ${ }^{1,4,5}$ \\ ${ }^{1}$ Division of Basic Sciences, ${ }^{2}$ Division of Clinical Research, Fred Hutchinson Cancer Research Center, Seattle, Washington \\ 98109, USA; ${ }^{3}$ Department of Pediatrics, ${ }^{4}$ Department of Radiation Oncology, University of Washington School of Medicine, \\ Seattle, Washington 98104, USA
}

To investigate the molecular basis of $\beta$-globin gene activation, we analyzed factor recruitment and histone modification at the adult $\beta$-globin gene in wild-type (WT)/locus control region knockout ( $\triangle \mathrm{LCR}$ ) heterozygous mice and in murine erythroleukemia (MEL) cells. Although histone acetylation and methylation (Lys 4) are high before and after MEL differentiation, recruitment of the erythroid-specific activator NF-E2 to the promoter and preinitiation complex (PIC) assembly occur only after differentiation. We reported previously that targeted deletion of the LCR reduces $\beta$-globin gene expression to $1 \%-4 \%$ of WT without affecting promoter histone acetylation. Here, we report that NF-E2 is recruited equally efficiently to the adult $\beta$-globin promoters of the $\triangle$ LCR and WT alleles. Moreover, the LCR deletion reduces PIC assembly only twofold, but has a dramatic effect on Ser 5 phosphorylation of RNA polymerase II and transcriptional elongation. Our results suggest at least three distinct stages in $\beta$-globin gene activation: (1) an LCR-independent chromatin opening stage prior to NF-E2 recruitment to the promoter and PIC assembly; (2) an intermediate stage in which NF-E2 binding (LCR-independent) and PIC assembly (partially LCR-dependent) occur; and (3) an LCR-dependent fully active stage characterized by efficient pol II elongation. Thus, in its native location the LCR functions primarily downstream of activator recruitment and PIC assembly.

[Keywords: Allele-specific chromatin immunoprecipitation analysis; locus control region; $\beta$-globin locus; transcription elongation; NF-E2; CTD-phosphorylation]

Supplemental material is available at http://www.genesdev.org.

Received January 6, 2003; revised version accepted February 19, 2003.

In higher eukaryotes, gene activation involves several events including chromatin opening, activator binding to regulatory regions, recruitment of basal transcription factors (TFIIA to TFII) and RNA polymerase II (pol II) to the promoter [preinitiation complex (PIC) assembly], and transcription elongation. A general model has emerged in which activators function to stabilize or modulate transcription through interactions with histone acetyltransferases, as well as components of the basal transcription machinery, such as TATA binding protein (TBP), TBP-associated factors (TAFs), and TFIIB (for review, see Lemon and Tjian 2000). PIC assembly is followed by initiation and elongation, during which the Cterminal domain (CTD) of the RPB1 subunit of pol II is phosphorylated (for review, see Dahmus 1996).

${ }^{5}$ Corresponding author.

E-MAIL markg@fhcrc.org; FAX (206) 667-5894.

Article published online ahead of print. Article and publication date are at http://www.genesdev.org/cgi/doi/10.1101/gad.1072303.
These steps in gene activation are often regulated by distal elements called enhancers (for review, see Blackwood and Kadonaga 1998; Martin 2001). Enhancers increase either the rate of transcription, the number of the templates engaged in transcription, or both. Studies using transgenes or in vitro templates have linked enhancer activities to various events such as PIC assembly (Kim et al. 1998; Yie et al. 1999), histone acetylation at the promoter (Madisen et al. 1998), and nuclear localization (Francastel et al. 1999). However, it is poorly understood which events in transactivation are the actual targets of long-range enhancer function at native gene loci.

The murine $\beta$-globin gene locus is a model system for studying the molecular mechanisms of enhancer-dependent gene activation at a native locus. The locus contains embryonic and adult $\beta$-like globin genes that are ordered as they are expressed during development. Highlevel expression of the $\beta$-globin gene cluster is regulated by the locus control region (LCR), which consists of several DNase I hypersensitive sites (HSs) distributed in the 
region $30-60 \mathrm{~kb}$ upstream of the adult $\beta^{\text {maj }}$ globin gene. Transient and stable transfection assays as well as studies in transgenic mice have suggested that the LCR not only enhances transcription but also has dominant chromatin opening activity (for review, see Bulger and Groudine 1999).

Surprisingly, studies of the targeted deletion of the LCR from the endogenous $\beta$-globin gene locus $(\Delta \mathrm{LCR})$ have revealed that the LCR is not required for the generalized DNaseI sensitive conformation of the locus or chromatin remodeling and histone hyperacetylation of the $\beta$-globin promoter (Epner et al. 1998; Bender et al. 2000; Schübeler et al. 2001); however, transcription from the $\Delta \mathrm{LCR}$ allele is decreased to $1 \%-4 \%$ of wild-type (WT) levels (Bender et al. 2000; Schübeler et al. 2001). These results suggest that the LCR stimulates transcription at an event downstream of promoter remodeling, although the molecular mechanism of LCR function has not been determined.

Several recent chromatin immunoprecipitation (ChIP) analyses of factor binding in the $\beta$-globin locus of cultured erythroid cell lines have provided clues to understanding the regulation of $\beta$-globin gene expression (for review, see Bulger et al. 2002). NF-E2, an erythroid-specific activator, appears to play an important role in $\beta$-globin expression by stimulating PIC assembly. NF-E2 is composed of two subunits: p45 NF-E2 and p18 NF-E2 (Andrews et al. 1993a, 1993b; Chan et al. 1993; Ney et al. 1993), the latter of which is a member of the small Maf protein family, MafK (Igarashi et al. 1994; for review, see Motohashi et al. 1997). p45 NF-E2, which contains a transactivation domain, interacts with TAFII130 (Amrolia et al. 1997) and CBP in vitro (Cheng et al. 1997; Hung et al. 2001) and is required for pol II recruitment to the $\beta^{m a j}$ globin gene promoter in mouse erythroleukemia (MEL) cells (Johnson et al. 2001). Recently, we reported that NF-E2 binds to both the LCR and the $\beta$-globin promoter region, even though no canonical NF-E2 binding sites are present in the promoter (Sawado et al. 2001). This observation has reinforced speculation that the LCR functions through interactions with the promoter.

To gain insight into which transcription events are influenced by the LCR, we have performed ChIP analyses of histone modifications and factor recruitment at the adult $\beta$-globin gene in two model systems: (1) differentiation of 745A MEL cells, a process accompanied by a greater than 100 -fold increase in $\beta$-globin gene expression (Sawado et al. 2001); and (2) primary erythroid cells derived from $\Delta \mathrm{LCR} / \mathrm{WT}$ heterozygous mice.

We find a high level of histone acetylation of the $\beta$-globin gene in uninduced MEL cells, and this does not change significantly upon differentiation. In contrast, significant binding of NF-E2, TFIIB, and pol II to the promoter, as well as efficient pol II elongation, is observed only in differentiated cells, consistent with the large increase in $\beta$-globin gene transcription. Analysis of wild-type and $\Delta$ LCR $\beta$-globin alleles in the $\Delta$ LCR/WT heterozygous mice suggests that NF-E2 binding to the $\beta$-globin promoter region occurs independent of the LCR, and that the LCR has only a small effect on PIC assembly. In contrast, deletion of the LCR dramatically decreases phosphorylation of the C-terminal domain (CTD) of pol II and pol II elongation, consistent with the large decrease in transcription observed. Our results suggest that the LCR plays multiple roles in the transition from an intermediate to a fully active stage, including a major effect on the transition from transcription initiation to elongation.

\section{Results}

Transcription factor recruitment to the promoter correlates with the conversion from basal to high level transcription during MEL cell induction

To gain insight into the pathway of $\beta$-globin gene activation, we analyzed recruitment of activators and components of the basal transcription machinery to the $\beta^{\text {maj }}$. globin gene in MEL cells. MEL cells are blocked at an early stage of erythropoiesis and morphologically resemble proerythroblasts. In MEL cell clone $745 \mathrm{~A}, \beta^{\text {maj }}$ globin gene transcripts are detectable in the uninduced state only by reverse transcriptase PCR (RT-PCR), and expression increases by $>100$-fold upon DMSO-mediated induction of terminal differentiation (Sawado et al. 2001). We performed ChIP with cross-linked chromatin from uninduced and differentiated MEL cells, using antibodies that recognize NF-E2, members of the PIC and histone modifications that are known markers for euchromatic genes. Using primer sets for the promoter region or exon 3 of the $\beta^{\text {maj }}$ globin gene, the enrichment of these factors/histone modifications at the $\beta^{\text {maj }}$ globin gene relative to myoD1 was determined by duplex PCR under conditions of linear amplification (Sawado et al. 2001). The myoD1 gene, which like the $\beta$-globin gene locus is located on murine chromosome 7 , is expressed only in skeletal muscle and its precursors (Weintraub et al. 1991); thus, it serves as a negative control. The ratio of the two PCR products was determined for the antibody-bound fraction and normalized to the ratio of the control IgG-bound fraction.

High levels of histone modifications such as acetylation of H3 (Lys 9 and/or Lys 14) and H4 (Lys 5, Lys 8, Lys 12, and/or Lys 16), dimethylation of H3 (Lys 4), which are known markers for euchromatic genes, are present at the promoter before induction and remain high throughout differentiation (Fig. 1; Sawado et al. 2001). In contrast, p45 NF-E2 recruitment is detectable only after induction (Fig. 1A,B), and the threefold enrichment in MafK binding at the $\beta^{\text {maj }}$ globin promoter before induction increases to $>20$-fold upon differentiation, as previously reported (Fig. 1A,B; Sawado et al. 2001). Consistent with the observation that NF-E2 is required for pol II recruitment (Johnson et al. 2001), high levels of pol II enrichment, as measured with an antibody that detects both phosphorylated and unphosphorylated forms, are detected only after induction. TFIIB, a component of the PIC, is enriched only 2.2-fold before induction, and this enrichment increases to 29.6-fold after induction (Fig. 1A,B). Pol II enrichment at the third exon of the $\beta^{m a j} g l_{0}$ - 

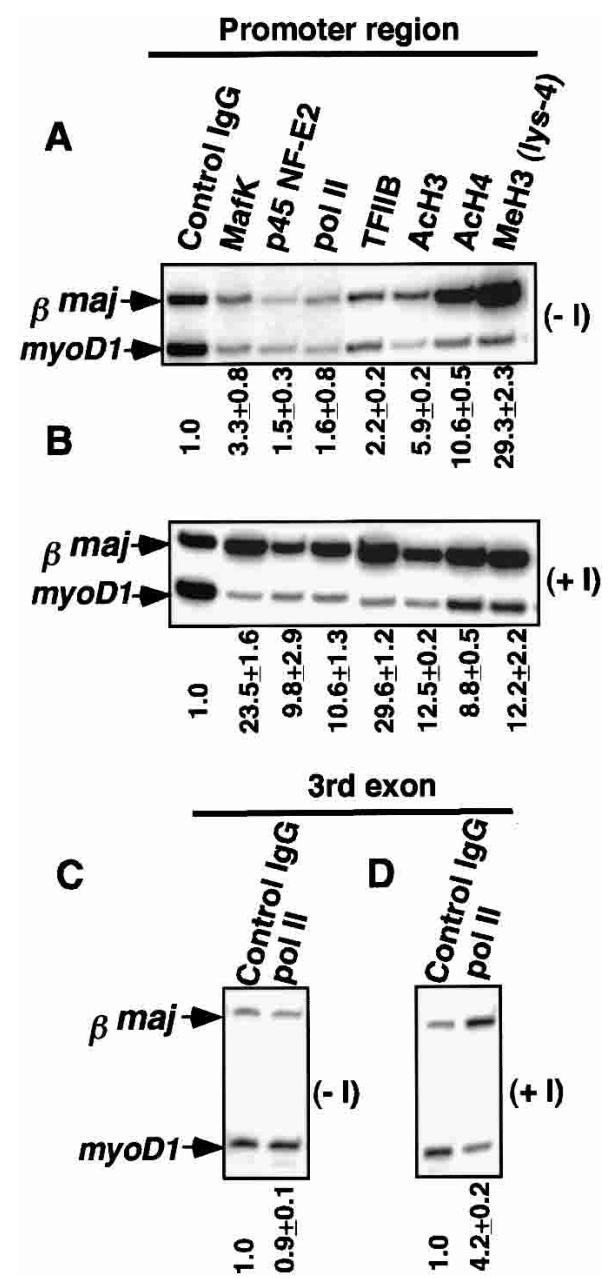

Figure 1. Factor recruitment and histone modifications at the $\beta^{\text {maj }}$ globin gene during MEL cell differentiation. Chromatin samples for immunoprecipitations were obtained from uninduced MEL cells $(A, C ;-\mathrm{I})$ and induced MEL cells $(B, D ;+\mathrm{I})$. Lanes are labeled with the antibodies used for ChIP. Duplex PCRs were performed with a primer set for myoD1 and a primer set for the promoter region $(A, B)$ or the third exon of the $\beta^{m a j}$ globin gene $(C, D)$. Enrichments relative to myoD1 are shown below the gels.

bin gene is also detectable after induction, indicating efficient transcription elongation (Fig. 1C). No enrichment of these factors or histone modifications is observed at the $\beta^{\text {maj }}$ globin gene in a pro-B cell line (data not shown). These results suggest that, in MEL cells, an "open" chromatin conformation is present prior to induction, and that ensuing steps such as NF-E2 complex formation, PIC assembly, and transcription elongation at the $\beta$-globin gene are distinct from chromatin opening and are correlated with high levels of expression.

\section{Allele-specific ChIP analysis for $\triangle L C R / W T$ heterozygous mice}

Analysis of targeted deletions of the endogenous $\beta$-globin LCR in mice and in cultured cells have revealed that the LCR is not required for initiation or maintenance of general DNase I sensitivity of the locus, hyperacetylation of histones, or low-level transcription, but it is essential for achieving high levels of transcription (Epner et al. 1998; Bender et al. 2000; Schübeler et al. 2001). Given the similar chromatin structure and expression of the $\beta$-globin loci in uninduced MEL cells and the $\triangle \mathrm{LCR}$ cells, we wished to determine if the differentiation-dependent events such as NF-E2 binding, PIC assembly, and elongation were LCR-dependent steps. Thus, we compared factor recruitment and histone modification at the $\Delta$ LCR with WT $\beta$-globin promoters in vivo.

We developed a novel ChIP assay that allows simultaneous determination of factor enrichment and histone modification in each $\beta$-globin allele in cells derived from $\Delta$ LCR/WT heterozygous mice (Fig. 2). There are two advantages in analyzing heterozygous mice. First, using allele specific ChIP analysis, the $\triangle \mathrm{LCR}$ and WT alleles are examined in the same ChIP reaction, allowing quantification of potentially subtle differences in factor recruitment or histone modification state between the WT and $\Delta$ LCR alleles. Second, by assessing factor recruitment or histone modification state in the same nuclear environment, we can exclude the possibility that differences in erythroid factor concentrations or the spectrum of erythroid cells present in the two homozygous mouse lines might bias assessment of factor enrichment or histone modification at one allele relative to the other.

To distinguish between binding at WT and $\triangle \mathrm{LCR}$ alleles of heterozygous mice in ChIPs, we used mice containing two different murine $\beta$-globin haplotypes, $\mathrm{Hbb}^{S}$ $(S)$ and $H b b^{D}(\mathrm{D}) \cdot \beta^{m a j}$ and $\beta^{S}$, which are the primary adult $\beta$-globin genes of the $\mathrm{D}$ and $\mathrm{S}$ alleles, respectively, are highly homologous; for example, the nucleotide sequence in the upstream promoter region of the two genes $(-249 \sim-1)$ is identical (data not shown). However, a $\beta^{S}$ specific HaeIII site is located $\sim 100$ bp downstream of the Cap site, and a $\beta^{m a j}$-specific BstXI site is located in the third exon (Fig. 2A; Fiering et al. 1995). ChIPs were performed using spleen cells from $\Delta$ LCR (D)/WT (S) heterozygous mice. After coamplification of both alleles with a single set of primers, the PCR products from the WT (S) and the $\triangle \mathrm{LCR}(\mathrm{D})$ alleles were digested with restriction enzymes recognizing these polymorphisms (Fig. 2B). The amount of a particular sequence in the antibody-bound chromatin was determined by duplex PCR and standardization to the amount of the myoD1 gene (not expressed in erythroid cells) in the bound fraction, as described previously (Sawado et al. 2001). Enrichment of signals from the WT $\left(\mathrm{E}_{\mathrm{WT}}\right)$ and $\triangle \mathrm{LCR}\left(\mathrm{E}_{\Delta \mathrm{LCR}}\right)$ alleles relative to myoD1 and the ratio of $\mathrm{E}_{\Delta \mathrm{LCR}}$ to $\mathrm{E}_{\mathrm{WT}}\left(\mathrm{E}_{\Delta \mathrm{LCR}} / \mathrm{E}_{\mathrm{WT}}\right)$ were determined as described in Materials and Methods.

NF-E2 and pol II recruitment to the $\beta$-globin promoter are LCR-independent

NF-E2 interacts not only with the LCR (Daftari et al. 1999; Forsberg et al. 2000; Sawado et al. 2001), but also with the promoter region, even though no canonical NF- 
Sawado et al.
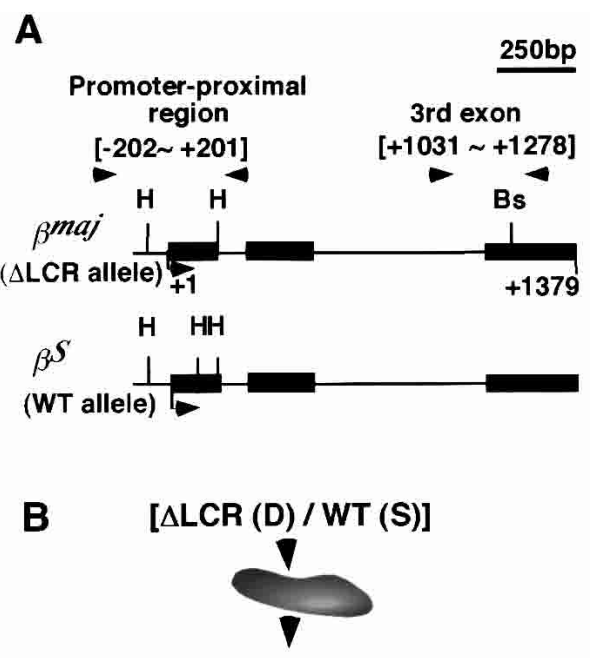

Crosslinking, IP, reverse-crosslinking

Duplex PCR amplification using globin and myoD1 primer pairs

$\checkmark$

Restriction enzyme digestion

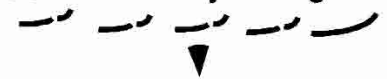

Loading on a polyacrylamide gel

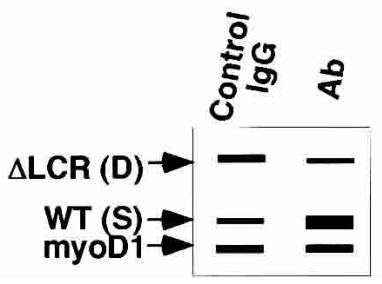

Figure 2. Allele-specific ChIP analysis. (A) Structures of the $\beta^{\text {maj }}$ globin and $\beta^{S}$ globin genes with polymorphisms for HaeIII (H) and the BstXI sites (Bs) are shown. PCR primer pairs for allele-specific ChIP analysis were designed to amplify both the $\beta^{m a j} g l o b i n$ and $\beta^{S}$ globin genes and are indicated by arrowheads. Positions are relative to the Cap site $(+1)$ of the $\beta^{m a j}$ globin gene. (B) An allele-specific ChIP analysis of $\Delta$ LCR (D)/WT (S) heterozygous mice is shown. Further details are presented in Materials and Methods.

E2 binding sites are present in the promoter (Sawado et al. 2001). Previously, we proposed two models for sequence-independent NF-E2 recruitment to the promoter: NF-E2 may be recruited to the promoter via interaction between the LCR and the promoter; alternatively, NF-E2 may reside in two independent protein complexes that bind to the LCR and the active promoters (Sawado et al. 2001). ChIP analyses of the WT and $\Delta$ LCR alleles in primary erythroid cells allow us to distinguish between these models.

Using allele specific ChIP analyses, we find that NF-E2

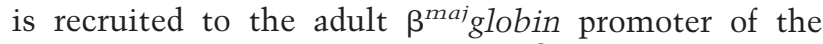
$\Delta \mathrm{LCR}$ allele as strongly as to the $\beta^{S}$ globin promoter of the WT allele (Fig. 3A). The ratio of enrichment on the $\Delta \mathrm{LCR}$ allele to WT $\left(\mathrm{E}_{\Delta \mathrm{LCR}} / \mathrm{E}_{\mathrm{WT}}\right)$ for MafK and $\mathrm{p} 45$ NF-E2 are 0.96 and 0.83 , respectively (Fig. $3 \mathrm{C}$ ). Therefore, NF-
E2 recruitment to the promoter is minimally affected by deletion of the LCR, and NF-E2 recruitment to the promoter is not dependent on an interaction between the
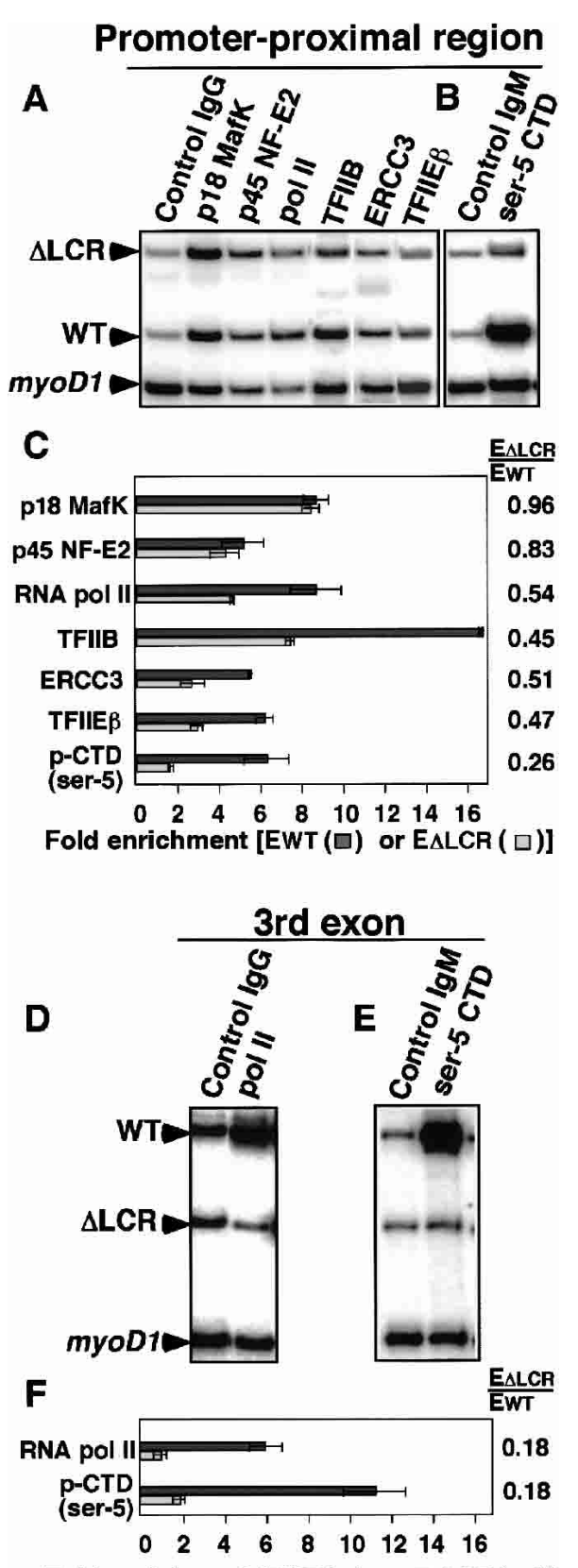

Figure 3. Allele-specific analysis of factor binding in the promoter-proximal region and third exon in $\Delta \mathrm{LCR}(\mathrm{D}) / \mathrm{WT}(\mathrm{S})$ heterozygous mice. Lanes are labeled with the antibody used. The regions tested are promoter-proximal $(A, B)$ and third exon $(D, E)$ of the $\beta^{\text {maj }}$ globin and $\beta^{S}$ globin genes. Enrichment of the $\beta$-globin gene relative to myoD1 in WT $\left(\mathrm{E}_{\mathrm{WT}}\right.$; indicated as dark-gray bars) or $\Delta \mathrm{LCR}\left(\mathrm{E}_{\triangle \mathrm{LCR}}\right.$ indicated as light-gray bars) alleles in sample materials relative to those in control IgG or IgM bound materials are shown in $C$ and $F$. The ratios between the WT and $\Delta \mathrm{LCR}$ allele PCR products $\left(\mathrm{E}_{\Delta \mathrm{LCR}} / \mathrm{E}_{\mathrm{wt}}\right)$ are shown at the right of graphs. A table showing these data is included in Supplemental Material. 
LCR and the promoter. We also found that pol II is significantly enriched at the promoter-proximal region even in the absence of the LCR (Fig. 3A), although this enrichment is reduced. $\mathrm{E}_{\Delta \mathrm{LCR}} / \mathrm{E}_{\mathrm{WT}}$ for pol II is 0.54 (Fig. $3 \mathrm{C})$, indicating that the number of pol II molecules in the promoter-proximal region of the $\Delta \mathrm{LCR}$ allele is $\sim 50 \%$ of WT.

To examine the possibility that the LCR in the WT allele promotes factor recruitment to the $\beta^{m a j}$ globin promoter of the $\triangle$ LCR allele in trans, we also performed the ChIP assays using WT or $\Delta$ LCR homozygous mice (Fig. 4). As shown, MafK, p45 NF-E2, and pol II were all enriched relative to $m y o D 1$ at the $\beta^{\text {maj }}$ globin promoterproximal region in both WT and $\Delta$ LCR loci (Fig. 4). In addition, and consistent with our previous analysis in MEL cells, both components of NF-E2 were enriched relative to myoD1 at HS2 in the WT locus (Fig. 4A).

\section{The LCR has only a twofold effect on PIC assembly}

Because the size of the chromatin used in these ChIP analyse is $300-800 \mathrm{bp}$, the $50 \%$ reduction in pol II enrichment in the $\Delta \mathrm{LCR}$ allele could occur at the level of pol II recruitment to the promoter and/or pol II elonga-

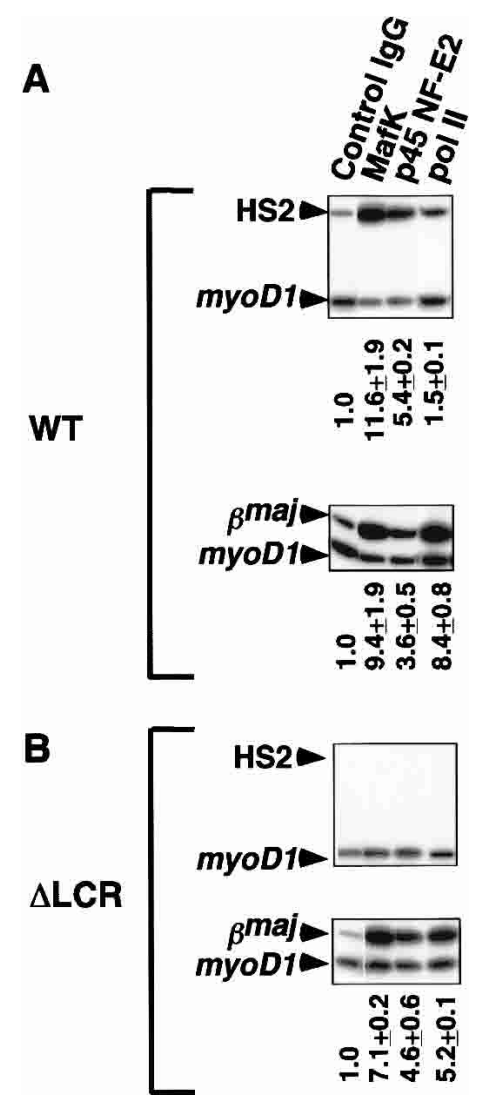

Figure 4. ChIP analysis of occupancy of NF-E2 and pol II at HS2 and the $\beta^{m a j}$ globin gene promoter in WT $(A)$ and $\Delta$ LCR $(B)$ homozygous mice. Chromatin were immunoprecipitated with control IgG, anti-p45 NF-E2, anti-MafK, and anti-pol II. Enrichment relative to myoD1 is shown below the gels. tion. To determine the effect of deletion of the LCR on PIC assembly, we determined the levels of general transcription factor (GTF) recruitment to the promoterproximal regions in the $\mathrm{WT}$ and $\Delta \mathrm{LCR}$ alleles. As shown in Figure 3A, TFIIB, a component of the PIC, is enriched in both WT and $\triangle \mathrm{LCR}$ alleles, although enrichment is reduced in the $\Delta \mathrm{LCR}$ allele (the $\mathrm{E}_{\Delta \mathrm{LCR}} / \mathrm{E}_{\mathrm{WT}}$ for TFIIB is 0.45; Fig. 3C). TFIIE and TFIIH stimulate promoter melting and promote the initial stage of transcription elongation (for review, see Hampsey 1998). Both TFIIE $\beta$, a subunit of TFIIE, and ERCC3, a helicase subunit of TFIIH, are enriched in both alleles (Fig. 3A). The $\mathrm{E}_{\Delta \mathrm{LCR}} /$ $\mathrm{E}_{\mathrm{WT}}$ for TFIIE $\beta$ is 0.47 and the $\mathrm{E}_{\Delta \mathrm{LCR}} / \mathrm{E}_{\mathrm{WT}}$ for ERCC3 is 0.51 (Fig. 3C). We obtained similar results for TFIIE $\alpha$, another subunit of TFIIE (data not shown). These results suggest that the LCR promotes PIC assembly approximately twofold. Importantly, despite dramatically decreased expression from the $\Delta \mathrm{LCR}$ allele $(1 \%-4 \%$ of $\mathrm{WT}$; Schübeler et al. 2001), recruitment of GTFs and pol II remains significant. This suggests that the LCR functions primarily at a step downstream of PIC assembly. Therefore, we investigated the possibility that transition from initiation to elongation is affected by the LCR deletion.

\section{The LCR acts primarily at the transition} from initiation to elongation

The high homology between the $5^{\prime}$ portions of the four adult $\beta$-globin genes in the D and $S$ alleles has precluded the use of conventional run-on assays to compare elongation efficiency in the $\beta$-globin locus of heterozygous mice. Therefore, we used allele-specific ChIP assays to compare pol II elongation efficiency in the $\beta^{m a j}$ and $\beta^{S}$ globin genes on $\Delta \mathrm{LCR}(\mathrm{D})$ and WT (S) alleles, respectively. In contrast to the nearly twofold higher enrichment of pol II in the promoter-proximal region in the WT compared to the $\triangle \mathrm{LCR}$ allele, we detected an at least fivefold higher enrichment of pol II in the third exon $\mid \sim 1$ $\mathrm{kb}$ downstream of the promoter) in the WT compared to the $\triangle \mathrm{LCR}$ allele. As shown in Figure $3 \mathrm{D}$ and F, pol II is enriched 6.1-fold in exon 3 in the WT allele, but no enrichment is observed in exon 3 in the $\Delta$ LCR allele. This result suggests that despite significant pol II recruitment to the promoter-proximal region of the $\Delta \mathrm{LCR}$ allele (Fig. 3A,C), no pol II enrichment is detectable at the third exon. Similarly, we detected significant enrichment of pol II $\sim 600$ bp downstream of the poly-A site in the WT, but not the $\triangle$ LCR allele (data not shown). These results suggest that pol II elongation is either blocked or inefficient in the absence of the LCR.

One prominent event during the transition from initiation to elongation is phosphorylation of the CTD of the RPB1 subunit of pol II (for review, see Dahmus 1996). Two residues in the CTD, Ser 2 and Ser 5, are known targets for phosphorylation during transcription enhanced by the HIV-1 long terminal repeat (Barboric et al. 2001), as well as transcription of several mammalian (Nissen and Yamamoto 2000; Soutoglou and Talianidis 2002) and yeast genes (Komarnitsky et al. 2000; Cho et 
al. 2001). In the $\beta$-globin locus, the Ser 5 phosphorylated form of CTD was shown to be enriched at the $\beta^{m a j}$ globin promoter after MEL cell induction (Johnson et al. 2001). To determine if CTD phosphorylation is affected by the LCR, we performed an allele-specific ChIP analysis using an antibody against the phosphorylated CTD. As shown in Figure 3B and C, Ser 5 phosphorylation of the CTD is present at the promoter-proximal region in the WT allele, but is significantly (fourfold) reduced in the $\Delta \mathrm{LCR}$ allele. These results suggest that even though pol II is enriched at the $\Delta \mathrm{LCR}$ promoter-proximal region (Fig. $3 \mathrm{~A})$, the CTD is not highly phosphorylated in the absence of the LCR.

The difference in CTD phosphorylation between the WT and the $\triangle \mathrm{LCR}$ alleles becomes even more prominent at the third exon (Fig. 3E,F), which is due in part to the relative inefficiency of pol II elongation in the $\Delta \mathrm{LCR}$ allele (Fig. 3D). Considering the slight reduction in pol II enrichment at the third exon in the WT allele, the increase of CTD phosphorylation of Ser 5 in the third exon is most likely due to hyperphosphorylation of the CTD (see Discussion).

\section{Discussion}

Mechanisms of NF-E2 recruitment to the promoter-proximal region

Previously we reported that subunits of NF-E2 are recruited to both the LCR and the promoter upon MEL cell induction (Sawado et al. 2001). Although there are multiple NF-E2 binding sites in the LCR, the promoter does not contain any canonical NF-E2 binding sites. Thus, NF-E2 may be recruited to the promoter via communication with the LCR, or NF-E2 may interact with both the LCR and the promoter independently (Sawado et al. 2001). Here, we find that NF-E2 recruitment to the promoter does not require the LCR. This result suggests that NF-E2 recruitment to the promoter may be mediated by interactions with proteins associated with the promoter-proximal region, for example, CBP /Cheng et al. 1997; Hung et al. 2001) and/or TafII130 (Amrolia et al. 1997).

\section{Three distinct stages of $\beta$-globin gene activation}

Together with our previous observations (Epner et al. 1998; Bender et al. 2000; Sawado et al. 2001; Schübeler et al. 2001), the results presented here suggest a three-step model for $\beta$-globin gene activation (Fig. 5). The first step is represented by uninduced MEL cells. Histone $\mathrm{H} 3$ and $\mathrm{H} 4$ acetylation, and $\mathrm{H} 3$ dimethylation (Lys 4) at the $\beta^{\text {maj }}$. globin promoter occur prior to formation of a functional NF-E2 complex and PIC. Interestingly, we find a twofold reduction in dimethylation of histone $\mathrm{H} 3$ at Lys 4 in the promoter region. It is not clear whether this modest decrease is due to conversion of the dimethyl to the trimethyl form of $\mathrm{H} 3$ upon high level of transcription, as recently suggested (Santos-Rosa et al. 2002) or caused by demethylation of H3. Regardless, in uninduced MEL

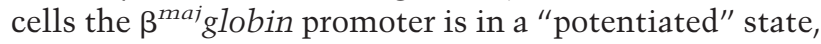

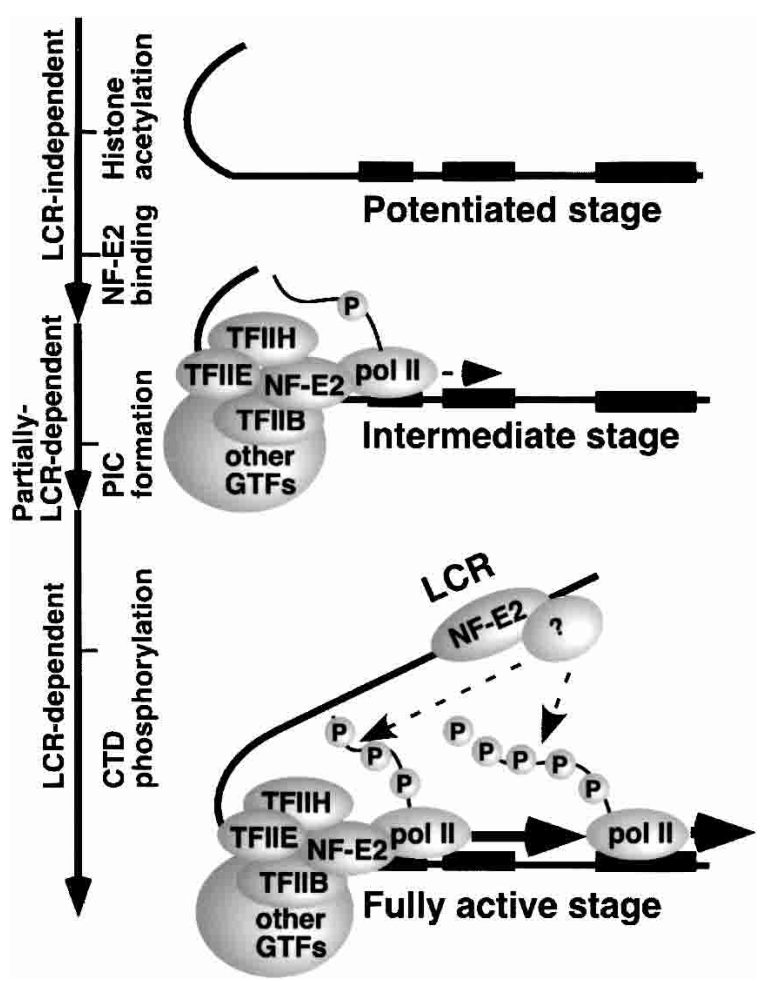

Figure 5. $\beta$-globin gene activation can be divided into three distinct steps. An LCR-independent potentiated stage is characterized by histone acetylation and methylation (Lys 4) in the absence of NF-E2 complex and PIC assembly at the promoter. An intermediate stage is characterized by LCR-independent NFE2 binding and partially LCR-dependent PIC assembly at the promoter. An LCR-dependent, fully active stage is characterized by CTD phosphorylation and efficient pol II elongation. The unknown factor (indicated by question mark) shown binding to the LCR may play a role in the transition to full activation (see Discussion). Each exon of adult $\beta$-globin is shown by a black bar.

but not active state. Previously we reported that neither histone acetylation (Schübeler et al. 2001) nor remodeling of the adult $\beta$-globin promoter (Epner et al. 1998; Bender et al. 2000) require the LCR. Using $\Delta$ LCR/S heterozygous mice, we find that NF-E2, pol II, and general transcription factors are recruited to the promoter-proximal region in the absence of the LCR. Thus, the status of the promoter on the $\Delta \mathrm{LCR}$ allele appears to represent an intermediate stage in the pathway that leads to fully activated transcription. The third step (fully active stage), characterized by high levels of CTD phosphorylation and efficient elongation, occurs in the WT but not the $\Delta$ LCR allele, and is thus LCR-dependent. In this model, the LCR functions primarily to promote the transition from the intermediate to fully active stage.

\section{Relationship between expression levels} and PIC assembly

In numerous genes in yeast, it has been shown that TBP and TFIIB binding are strictly correlated with transcrip- 
tion levels (Kuras and Struhl 1999; Li et al. 1999); however, we find that removal of the LCR leads to only a twofold reduction in recruitment of GTFs and pol II to the promoter, while the rate of transcription is reduced 25- to 100-fold (Schübeler et al. 2001). Therefore, PIC assembly does not reflect the level of expression in the $\beta$-globin gene locus. Similar inconsistencies between expression level and PIC assembly were observed in the HMRa1 and HSP82 genes in yeast, where PIC assembly takes place even in silent chromatin (Sekinger and Gross 2001). In a small subset of yeast promoters, TBP binding is high even when gene activity is low and increases only modestly with high expression levels (Kuras and Struhl 1999|. Also, GTFs bind to Drosophila promoters that are repressed by Polycomb group proteins (Breiling et al. 2001). It has been shown that chromatin remodeling of the $\alpha 1$-antitrypsin gene promoter occurs after PIC assembly (Soutoglou and Talianidis 2002), and that elongation is the rate-limiting step in the regulation of many genes, including c-myc (Bentley and Groudine 1986; Krumm et al. 1992), c-fos (Plet et al. 1995), heat-shock protein (Brown et al. 1996; Lis 1998), and transcription regulated by the HIV-1 LTR (Marciniak and Sharp 1991; for review, see Jones and Peterlin 1994). These observations demonstrate that events downstream of PIC assembly can be rate-limiting steps in transcription, and may represent common mechanisms for establishing an active state in many genes. Surprisingly, our results reveal that the $\beta$-globin LCR functions primarily at just such downstream steps, because it mediates the transition from a state defined by PIC assembly, low CTD phosphorylation and inefficient elongation to a fully active stage.

Our results implicating a primary function of the LCR downstream of PIC assembly contrast with a recent report showing that the endogenous $3^{\prime} T C R \beta$ enhancer $(\mathrm{E} \beta)$ acts to modify chromatin and in the recruitment of pol II, TBP, and transactivators at the upstream $p D \beta 1$ promoter (Spicuglia et al. 2002). Clearly, these differences could be due to different technical approaches (e.g., ChIP procedures). However, the order of chromatin modification and factor recruitment is not the same at different gene loci (Cosma et al. 1999; Agalioti et al. 2000), and this may reflect different enhancer-mediated steps in gene activation.

\section{LCR-dependent CTD phosphorylation}

One major effect of the LCR is CTD phosphorylation at Ser 5, which is required for the transition from transcription initiation to elongation. We find that although basal levels of CTD phosphorylation can be detected at the $\Delta$ LCR allele, high-level CTD phosphorylation requires the LCR. Our observation that CTD hyperphosphorylation of Ser 5 is detected at the $3^{\prime}$ end of the gene does not correlate with previous analyses of several yeast genes (Komarnitsky et al. 2000; Cho et al. 2001) and the human $\alpha 1$-antitrypsin gene (Soutoglou and Talianidis 2002). In these genes, the Ser 5 phosphorylated form of the CTD is enriched only at the promoter-proximal region, and not at the $3^{\prime}$ end, whereas Ser 2 phosphorylated CTD is detected at the $3^{\prime}$ end. Despite using several different antibodies, we failed to detect the Ser 2 phosphorylated form of the CTD in the $\beta$-globin gene in murine erythroid cells, and Ser 2 phosphorylation of the CTD is not observed in the myoD1 gene in murine muscle cells (B. Penn and S. Tapscott, unpubl.). Moreover, hyperphosphorylation at Ser 5 of the CTD, in the absence of Ser 2 phosphorylation, is sufficient for optimal transcription of the Drosophila sgs genes (Kaplan et al. 2000).

Several CTD-kinases such as TFIIH-associated kinase (cdk7), cdk8, and positive transcription elongation factor b (P-TEFb) associated kinase (cdk9) are known to phosphorylate CTD at Ser 5 in vivo (for review, see Prelich 2002). Although it remains to be determined which CTD kinase(s) is/are responsible for activation of the $\beta$-globin gene, one possibility is that LCR-bound factors may stimulate CTD kinase activity in the protein complex at the $\beta$-globin gene. Alternatively, a CTD kinase associated with the LCR may be directly recruited to the $\beta^{\text {maj }}$. globin gene and promote pol II elongation (Fig. 5).

\section{Materials and Methods}

\section{Cell lines, culture conditions, and antibodies}

The 745A MEL cell line was cultured and induced by DMSO as described previously (Sawado et al. 2001). Control IgG (normal IgG), anti-p45 NF-E2, anti-MafK (p18 NF-E2), anti-pol II (for both phosphorylated and unphosphorylated form), and antiTFIIB, anti-ERCC3, and anti-TFIIE $\alpha$, and anti-TFIIE $\beta$ were obtained from Santa Cruz Biotechnology. H14, an anti-CTD of RPB1 (phosphorylated at Ser 5) IgM was obtained from Covance. Antiacetylated H3 (Lys 9 and/or Lys 14), antiacetylated H4 (Lys 5, Lys 8, Lys 12, and/or Lys 16), antidimethylated H3 (Lys 4) were obtained from Upstate Biotech. Control IgM (clone K76) was a gift from Dr. M. Roth (Fred Hutchinson Cancer Research Center, Seattle, WA).

\section{ChIP using MEL cells}

Chromatin fixation and immunoprecipitation procedures were as described (Shang et al. 2000). Duplex PCR reactions and quantifications were performed as described (Sawado et al. 2001).

Conventional or allele-specific ChIP analyses using mouse splenic cells

Two alleles of the murine $\beta$-globin gene, $H b b^{D}(\mathrm{D})$ and $H b b^{S}(\mathrm{~S})$, were analyzed in this study. Previously we showed that the expression level of the adult $\beta$-globin from D and $S$ alleles in $\mathrm{WT}(\mathrm{D}) / \mathrm{WT}(\mathrm{S})$ mice is quite similar (Fiering et al. 1995). In this study the D allele contains the $\Delta$ LCR mutation, while the WT (S) allele is used as a control. For ChIP assays using homozygous mice, we used WT and $\triangle \mathrm{LCR}$ mice with D alleles. Both strains were also homozygous for a YAC expressing the human $\beta$-globin gene $(\mathrm{H})$ as $\triangle$ LCR homozygous mice are not viable (Bender et al. 2000). For allele-specific analyses, heterozygous mutant mice $\Delta$ LCR (D)/WT (S) with or without one copy of the YAC (H) were used and gave identical results. To increase the erythroid cell population in spleens, $\Delta \mathrm{LCR}(\mathrm{D}) / \mathrm{WT}(\mathrm{S})$-H mice were treated with phenylhydrazine (PHZ) for $3 \mathrm{~d}$ and the spleens were harvested on day 6 (Reitman and Felsenfeld 1990). The spleens 
of $\Delta$ LCR (D)/WT (S) mice consist primarily of erythroid cells thus, PHZ was not used. Spleens were harvested from mice and disrupted in RPMI media containing $2 \%$ fetal calf serum to prepare a single cell suspension. After passage through a $70-\mu \mathrm{m}$ Nylon cell strainer (Falcon), cells were washed once with PBS containing $2 \%$ serum and were fixed with $1 \%$ formaldehyde for $5 \mathrm{~min}$ at room temperature in PBS containing $2 \%$ serum. The cross-linking reaction was terminated by adding $1 / 20$ volume of $2.5 \mathrm{M}$ glycine. Cells were washed twice with ice-cold PBS containing $2 \%$ serum and then lysed in buffer containing $1 \%$ SDS, $5 \mathrm{mM}$ EDTA, and $50 \mathrm{mM}$ Tris- $\mathrm{HCl}$ (pH 8.1). Chromatin samples were sonicated to obtain 300-800 bp DNA fragments. Samples were diluted 10 -fold by adding buffer containing $1 \%$ Triton $\mathrm{X}-100,2 \mathrm{mM}$ EDTA, $150 \mathrm{mM} \mathrm{NaCl}$, and $20 \mathrm{mM}$ Tris- $\mathrm{HCl}(\mathrm{pH}$ 8.1). For all the antibodies except IgMs, chromatin was incubated with normal serum (Jackson Immunoresearch), protein A/G beads in the presence of $20 \mu \mathrm{g} / \mathrm{mL}$ of salmon sperm DNA. Following centrifugation to remove $\mathrm{A} / \mathrm{G}$ beads, antibodies were added to the supernatant and incubated overnight at $4^{\circ} \mathrm{C}$. Samples were then incubated with preblocked beads for $1 \mathrm{~h}$. To harvest immunoprecipitated chromatin, beads were sequentially washed with buffer I $(0.1 \%$ SDS, $1 \%$ Triton X-100, 2 mM EDTA, $20 \mathrm{mM}$ Tris- $\mathrm{HCl}$ at $\mathrm{pH} 8.1,150 \mathrm{mM} \mathrm{NaCl}$ ), buffer II (0.1\% SDS, $1 \%$ Triton X-100, $2 \mathrm{mM}$ EDTA, $20 \mathrm{mM}$ Tris- $\mathrm{HCl}$ at $\mathrm{pH} 8.1$, and $500 \mathrm{mM} \mathrm{NaCl}$ ), buffer III (0.25 M LiCl, 1\% NP-40, $1 \%$ deoxycholate, $1 \mathrm{mM}$ EDTA, $10 \mathrm{mM}$ Tris- $\mathrm{HCl}$ at $\mathrm{pH} 8.1$ ), and then twice with TE. Chromatin was eluted from the beads by washing with elution buffer containing $1 \%$ SDS, $0.1 \mathrm{M}$ $\mathrm{NaHCO}_{3}$, and $0.1 \mathrm{mg} / \mathrm{mL}$ of proteinase K. Soluble chromatin was reverse-cross-linked overnight in elution buffer overnight at $65^{\circ} \mathrm{C}$. DNA was purified using a PCR purification kit (Qiagen). All of the solutions, except TE washes and elution buffer, contain phosphatase inhibitors (microcystin, sodium fluoride, and sodium vanadate), a proteinase inhibitor cocktail (Roche), and histone deacetylase inhibitor (sodium butyrate).

For antiphosphorylated pol II IgM, we used another ChIP procedure described by Nissen and Yamamoto (2000) with minor modifications.

\section{Semiquantitative PCR for allele-specific analyses}

Duplex PCR reactions were performed in $1 \times$ buffer II (Applied Biosystems), $1.25 \mathrm{mM} \mathrm{MgCl}_{2}, 0.2 \mathrm{mM} \mathrm{dNTP}, 5-10$ pmole of each globin gene primer set, 5 pmole of the myoD1 gene primer set, $1 \mu \mathrm{Ci}\left[\alpha^{3}{ }^{32} \mathrm{P}\right] \mathrm{dCTP}$, and 0.05 units of AmpliTaq Gold. The PCR reaction included one cycle of $10 \mathrm{~min}$ at $95^{\circ} \mathrm{C}$, followed by 30 or 31 cycles of $96^{\circ} \mathrm{C}$ for $30 \mathrm{sec}, 54^{\circ} \mathrm{C}$ for $30 \mathrm{sec}$, and $72^{\circ} \mathrm{C}$ for $30 \mathrm{sec}$. For allele specific analysis, PCR products were digested with HaeIII for the promoter-proximal region, or BstXI for the third exon of the $\beta$-globin gene. All the PCR reactions were performed within the range of linear amplification. The PCR products were separated on a $6 \%$ polyacrylamide gel. Quantification of the ChIP results using homozygous mice was done as described previously (Sawado et al. 2001; Schübeler et al. 2001). Quantification of allele-specific analysis was performed as follows.

Enrichment of the $\beta$-globin gene relative to myoD1 in WT $\left(\mathrm{E}_{\mathrm{WT}}\right)$ or $\Delta \mathrm{LCR}\left(\mathrm{E}_{\Delta \mathrm{LCR}}\right)$ alleles in sample materials relative to those in control IgG bound materials were calculated by:

$$
\begin{aligned}
& \text { ([ } \beta \text {-globin signal }] \times \mathrm{CWT} \text { or } \mathrm{C} \Delta \mathrm{LCR}) / \\
& \text { EWT or } \mathrm{E} \Delta \mathrm{LCR}=\frac{([\mathrm{myoD} 1 \text { signal }]) \text { sample signal }}{([\beta \text {-globin signal }] \times \mathrm{CWT} \text { or } \mathrm{C} \Delta \mathrm{LCR}) /} \\
& \text { ([myoD1 signal] }) \text { Control IgG signals }
\end{aligned}
$$

To account for differences in incorporation of $\left[\alpha-{ }^{32} \mathrm{P}\right] \mathrm{dCTP}$, constant values for the $\mathrm{WT}\left(\mathrm{C}_{\mathrm{WT}}\right)$ or $\Delta \mathrm{LCR}\left(\mathrm{C}_{\Delta \mathrm{LCR}}\right)$ alleles were determined based on GC contents of PCR products from each allele. For the adult $\beta$-globin promoters, $\mathrm{C}_{\mathrm{WT}}$ and $\mathrm{C}_{\Delta \mathrm{LCR}}$ are 1.25 and 1.0, respectively. For the third exon of the adult $\beta$-globin gene, $\mathrm{C}_{\mathrm{WT}}$ and $\mathrm{C}_{\Delta \mathrm{LCR}}$ are 1.00 and 1.26 , respectively. ChIP experiments were perfomed at least twice and the standard deviation for each value was determined. When the enrichment from both alleles was significantly high (more than twofold, relative to myoD1), the ratio between the WT and $\triangle \mathrm{LCR}$ alleles in PCR products $\left(\mathrm{E}_{\Delta \mathrm{LCR}} / \mathrm{E}_{\mathrm{wt}}\right)$ was determined to be significant.

Oligonucleotides for ChIP using homozygous mice and MEL cells were as described previously (Sawado et al. 2001). Oligonucleotide pairs for PCRs using the heterozygous mice were as follows: myoD1 gene (268 bp), md2176, TTCCAGTCTAGCA AGTCCTCAGTT; myoD-s-, TTAGGGATGCCCCCTCTGG CGGA. Digestion of the myoD1 gene with HaeIII or BstXI yields products of 148 and $74 \mathrm{bp}, 47 \mathrm{bp}$, or 169 and $100 \mathrm{bp}$, respectively. The primer pairs for the $\beta^{m a j}$ and $\beta^{S}$ globin promoter-proximal regions (403 bp) were, $\beta_{-}{ }^{m a j+}$, GACAAACAT TATTCAGAGGGAGTA; 114706-114728, TGTCTCCAAGCA CCCAACTTCTT.

Digestion of the D allele with HaeIII yields products of 211 , 127 , and $65 \mathrm{bp}$, while the S-allele yields 170, 127, 41, and $65 \mathrm{bp}$. Primer pairs for the 3 -exon of $\beta^{\text {maj }}$ and $\beta^{S}$ globin genes (270/273 bp) were: 115558-15583, TAATTTGTCAGTAGTTTAAGGTT GCA; 115827-15805, CATTGTTCACAGGCAAGAGCAGG.

Digestion of the D allele with BstXI yields products of 217 and $53 \mathrm{bp}$, while the S-allele yields a 273-bp product. Linear amplification in duplex PCR reaction was confirmed for each primer pair. All globin primer pairs were designed to amplify only the $\beta^{m a j}$ and $\beta^{S}$ globin genes without coamplification of the two minor adult globin genes $\left(\beta^{\text {min }}\right.$ and $\left.\beta^{t}\right)$ or the human $\beta$-globin genes in YAC.

\section{Acknowledgment}

This work was supported by a fellowship from the Uehara memorial foundation (T.S.), a grant from the Cooley's Anemia Foundation (M.A.B.), an American Society of Hematology Scholar Award (M.A.B.), and NIH Grants DK44746 and HL57620 (M.G.). We thank Drs. Myles Brown and Stephen Buratowski (Harvard Medical School) for technical advice and discussion; Dr. Anton Krumm (Seattle V.A. Hospital) for helpful discussions; Rachel Byron, Andrew Gingras, and Wendy Paulsene (FHCRC) for technical assistance; and Drs. Steve Hahn, Tobias Ragoczy, Mike Bulger, Dirk Schübeler, and Fred van Leeuwen (Fred Hutchinson Cancer Research Center) for critical reading of the manuscript.

The publication costs of this article were defrayed in part by payment of page charges. This article must therefore be hereby marked "advertisement" in accordance with 18 USC section 1734 solely to indicate this fact.

\section{References}

Agalioti, T., Lomvardas, S., Parekh, B., Yie, J., Maniatis, T., and Thanos, D. 2000. Ordered recruitment of chromatin modifying and general transcription factors to the IFN-beta promoter. Cell 103: 667-678.

Amrolia, P.J., Ramamurthy, L., Saluja, D., Tanese, T., Jane, S.M., and Cunningham, J.M. 1997. The activation domain of the enhancer binding protein p45NF-E2 interacts with TAFII130 and mediates long-range activation of the $\alpha$ - and $\beta$-globin gene loci in an erythroid cell line. Proc. Natl. Acad. Sci. 94: 10051-10056. 
Andrews, N.C., Erdjument-Bromage, H., Davidson, M.B., Tempst, P., and Orkin, S.H. 1993a. Erythroid transcription factor NF-E2 is a haematopoietic-specific basic-leucine zipper protein. Nature 362: 722-728.

Andrews, N.C., Kotkow, K.J., Ney, P.A., Erdjument-Bromage, H., Tempst, P., and Orkin, S.H. 1993b. The ubiquitous subunit of erythroid transcription factor NF-E2 is a small basicleucine zipper protein related to the v-maf oncogene. Proc. Natl. Acad. Sci. 90: 11488-11492.

Barboric, M., Nissen, R.M., Kanazawa, S., Jabrane-Ferrat, N., and Peterlin, B.M. 2001. NF-кB binds P-TEFb to stimulate transcriptional elongation by RNA polymerase II. Mol. Cell 8: 327-337.

Bender, M.A., Bulger, M., Close, J., and Groudine, M. 2000. $\beta$-globin gene switching and DNase I sensitivity of the endogenous $\beta$-globin locus in mice do not require the locus control region. Mol. Cell 5: 387-393.

Bentley, D.L. and Groudine, M. 1986. A block to elongation is largely responsible for decreased transcription of c-myc in differentiated HL60 cells. Nature 321: 702-706.

Blackwood, E.M. and Kadonaga, J.T. 1998. Going the distance: A current view of enhancer action. Science 281: 61-63.

Breiling, A., Turner, B.M., Bianchi, M.E., and Orlando, V. 2001. General transcription factors bind promoters repressed by Polycomb group proteins. Nature 412: 651-655.

Brown, S.A., Imbalzano, A.N., and Kingston, R.E. 1996. Activator-dependent regulation of transcriptional pausing on nucleosomal templates. Genes \& Dev. 10: 1479-1490.

Bulger, M. and Groudine, M. 1999. Looping versus linking: Toward a model for long-distance gene activation. Genes \& Dev. 13: 2465-2477.

Bulger, M., Sawado, T., Schübeler, D., and Groudine, M. 2002. ChIPs of the $\beta$-globin locus: Unraveling gene regulation within an active domain. Curr. Opin. Genet. Dev. 12: 170 177.

Chan, J.Y., Han, X.L., and Kan, Y.W. 1993. Isolation of cDNA encoding the human NF-E2 protein. Proc. Natl. Acad. Sci. 90: 11366-11370.

Cheng, X., Reginato, M.J., Andrews, N.C., and Lazar, M.A. 1997. The transcriptional integrator CREB-binding protein mediates positive cross talk between nuclear hormone receptors and the hematopoietic bZip protein p45/NF-E2. Mol. Cell Biol. 17: 1407-1416.

Cho, E.J., Kobor, M.S., Kim, M., Greenblatt, J., and Buratowski, S. 2001. Opposing effects of Ctk1 kinase and Fcp1 phosphatase at Ser 2 of the RNA polymerase II C-terminal domain. Genes \& Dev. 15: 3319-3329.

Cosma, M.P., Tanaka, T., and Nasmyth, K. 1999. Ordered recruitment of transcription and chromatin remodeling factors to a cell cycle- and developmentally regulated promoter. Cell 97: 299-311.

Daftari, P., Gavva, N.R., and Shen, C.K. 1999. Distinction between AP1 and NF-E2 factor-binding at specific chromatin regions in mammalian cells. Oncogene 18: 5482-5486.

Dahmus, M.E. 1996. Reversible phosphorylation of the C-terminal domain of RNA polymerase II. I. Biol. Chem. 271: 19009-19012.

Epner, E., Reik, A., Cimbora, D., Telling, A., Bender, M.A., Fiering, S., Enver, T., Martin, D.I., Kennedy, M., Keller, G., et al. 1998. The $\beta$-globin LCR is not necessary for an open chromatin structure or developmentally regulated transcription of the native mouse $\beta$-globin locus. Mol. Cell 2: 447455.

Fiering, S., Epner, E., Robinson, K., Zhuang, Y., Telling, A., Hu, M., Martin, D.I., Enver, T., Ley, T.J., and Groudine, M. 1995. Targeted deletion of $5^{\prime} \mathrm{HS} 2$ of the murine $\beta$-globin LCR re- veals that it is not essential for proper regulation of the $\beta$-globin locus. Genes \& Dev. 9: 2203-2213.

Forsberg, E.C., Downs, K.M., and Bresnick, E.H. 2000. Direct interaction of NF-E2 with hypersensitive site 2 of the $\beta$-globin locus control region in living cells. Blood 96: 334-339.

Francastel, C., Walters, M.C., Groudine, M., and Martin, D.I. 1999. A functional enhancer suppresses silencing of a transgene and prevents its localization close to centrometric heterochromatin. Cell 99: 259-269.

Hampsey, M. 1998. Molecular genetics of the RNA polymerase II general transcriptional machinery. Microbiol. Mol. Biol. Rev. 62: 465-503.

Hung, H.L., Kim, A.Y., Hong, W., Rakowski, C., and Blobel, G.A. 2001. Stimulation of nf-e2 dna binding by creb-binding protein (cbp)-mediated acetylation. I. Biol. Chem. 276: 10715-10721.

Igarashi, K., Kataoka, K., Itoh, K., Hayashi, N., Nishizawa, M., and Yamamoto, M. 1994. Regulation of transcription by dimerization of erythroid factor NF-E2 p45 with small Maf proteins. Nature 367: 568-572.

Johnson, K.D., Christensen, H.M., Zhao, B., and Bresnick, E.H. 2001. Distinct mechanisms control RNA polymerase II recruitment to a tissue-specific locus control region and a downstream promoter. Mol. Cell 8: 465-471.

Jones, K.A. and Peterlin, B.M. 1994. Control of RNA initiation and elongation at the HIV-1 promoter. Annu. Rev. Biochem. 63: 717-743.

Kaplan, C.D., Morris, J.R., Wu, C., and Winston, F. 2000. Spt5 and spt6 are associated with active transcription and have characteristics of general elongation factors in D. melanogaster. Genes \& Dev. 14: 2623-2634.

Kim, T.K., Kim, T.H., and Maniatis, T. 1998. Efficient recruitment of TFIIB and CBP-RNA polymerase II holoenzyme by an interferon- $\beta$ enhanceosome in vitro. Proc. Natl. Acad. Sci. 95: 12191-12196.

Komarnitsky, P., Cho, E.J., and Buratowski, S. 2000. Different phosphorylated forms of RNA polymerase II and associated mRNA processing factors during transcription. Genes \& Dev. 14: 2452-2460.

Krumm, A., Meulia, T., Brunvand, M., and Groudine, M. 1992. The block to transcriptional elongation within the human c-myc gene is determined in the promoter-proximal region. Genes \& Dev. 6: 2201-2213.

Kuras, L. and Struhl, K. 1999. Binding of TBP to promoters in vivo is stimulated by activators and requires Pol II holoenzyme. Nature 399: 609-613.

Lemon, B. and Tjian, R. 2000. Orchestrated response: A symphony of transcription factors for gene control. Genes \& Dev. 14: 2551-2269.

Li, X.Y., Virbasius, A., Zhu, X., and Green, M.R. 1999. Enhancement of TBP binding by activators and general transcription factors. Nature 399: 605-609.

Lis, J. 1998. Promoter-associated pausing in promoter architecture and postinitiation transcriptional regulation. Cold Spring Harb. Symp. Quant. Biol. 63: 347-356.

Madisen, L., Krumm, A., Hebbes, T.R., and Groudine, M. 1998. The immunoglobulin heavy chain locus control region increases histone acetylation along linked c-myc genes. Mol. Cell. Biol. 18: 6281-6292.

Marciniak, R.A. and Sharp, P.A. 1991. HIV-1 Tat protein promotes formation of more-processive elongation complexes. EMBO T. 10: 4189-4196.

Martin, D.I. 2001. Transcriptional enhancers-On/off gene regulation as an adaptation to silencing in higher eukaryotic nuclei. Trends Genet. 17: 444-448.

Motohashi, H., Shavit, J.A., Igarashi, K., Yamamoto, M., and 
Sawado et al.

Engel, J.D. 1997. The world according to Maf. Nucleic Acids Res. 25: 2953-2959.

Ney, P.A., Andrews, N.C., Jane, S.M., Safer, B., Purucker, M.E., Weremowicz, S., Morton, C.C., Goff, S.C., Orkin, S.H., and Nienhuis, A.W. 1993. Purification of the human NF-E2 complex: cDNA cloning of the hematopoietic cell-specific subunit and evidence for an associated partner. Mol. Cell. Biol. 13: $5604-5612$.

Nissen, R.M. and Yamamoto, K.R. 2000. The glucocorticoid receptor inhibits NFkB by interfering with serine-2 phosphorylation of the RNA polymerase II carboxy-terminal domain. Genes \& Dev. 14: 2314-2329.

Plet, A., Eick, D., and Blanchard, J.M. 1995. Elongation and premature termination of transcripts initiated from c-fos and c-myc promoters show dissimilar patterns. Oncogene 10: $319-328$,

Prelich, G. 2002. RNA polymerase II carboxy-terminal domain kinases: Emerging clues to their function. Eukaryot. Cell 1: 153-162.

Reitman, M. and Felsenfeld, G. 1990. Developmental regulation of topoisomerase II sites and DNase I-hypersensitive sites in the chicken $\beta$-globin locus. Mol. Cell. Biol. 10: 2774-2786.

Santos-Rosa, H., Schneider, R., Bannister, A.J., Sherriff, J., Bernstein, B.E., Emre, N.C., Schreiber, S.L., Mellor, J., and Kouzarides, T. 2002. Active genes are tri-methylated at K4 of histone H3. Nature 419: 407-411.

Sawado, T., Igarashi, K., and Groudine, M. 2001. Activation of $\beta$-major globin gene transcription is associated with recruitment of NF-E2 to the $\beta$-globin LCR and gene promoter. Proc. Natl. Acad. Sci. 98: 10226-10231.

Schübeler, D., Groudine, M., and Bender, M.A. 2001. The murine $\beta$-globin locus control region regulates the rate of transcription but not the hyperacetylation of histones at the active genes. Proc. Natl. Acad. Sci. 98: 11432-11437.

Sekinger, E.A. and Gross, D.S. 2001. Silenced chromatin is permissive to activator binding and PIC recruitment. Cell 105: 403-414.

Shang, Y., Hu, X., DiRenzo, J., Lazar, M.A., and Brown, M. 2000. Cofactor dynamics and sufficiency in estrogen receptorregulated transcription. Cell 103: 843-852.

Soutoglou, E. and Talianidis, I. 2002. Coordination of PIC assembly and chromatin remodeling during differentiation-induced gene activation. Science 295: 1901-1904.

Spicuglia, S., Kumar, S., Yeh, J.H., Vachez, E., Chasson, L., Gorbatch, S., Cautres, J., and Ferrier, P. 2002. Promoter activation by enhancer-dependent and -independent loading of activator and coactivator complexes. Mol. Cell 10: 1479-1487.

Weintraub, H., Davis, R., Tapscott, S., Thayer, M., Krause, M., Benezra, R., Blackwell, T.K., Turner, D., Rupp, R., Hollenberg, S., et al. 1991. The myoD gene family: Nodal point during specification of the muscle cell lineage. Science 251: 761-766.

Yie, J., Senger, K., and Thanos, D. 1999. Mechanism by which the IFN- $\beta$ enhanceosome activates transcription. Proc. Natl. Acad. Sci. 96: 13108-13113. 


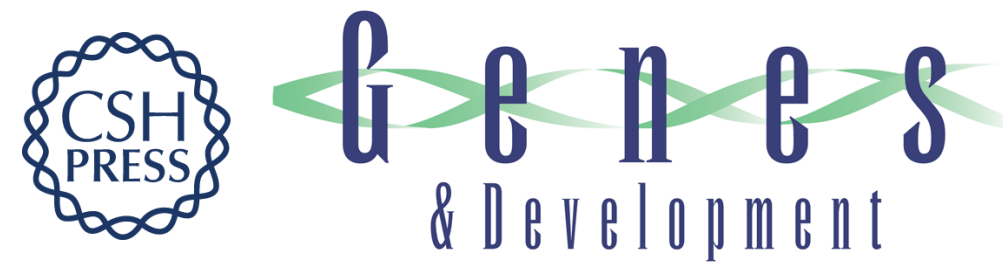

\section{The $\beta$-globin locus control region (LCR) functions primarily by enhancing the transition from transcription initiation to elongation}

Tomoyuki Sawado, Jessica Halow, M.A. Bender, et al.

Genes Dev. 2003, 17:

Access the most recent version at doi:10.1101/gad.1072303

Supplemental http://genesdev.cshlp.org/content/suppl/2003/04/25/U-10723R.DC1
Material

References This article cites 52 articles, 27 of which can be accessed free at:

http://genesdev.cshlp.org/content/17/8/1009.full.html\#ref-list-1

License

Email Alerting Receive free email alerts when new articles cite this article - sign up in the box at the top

Service right corner of the article or click here.

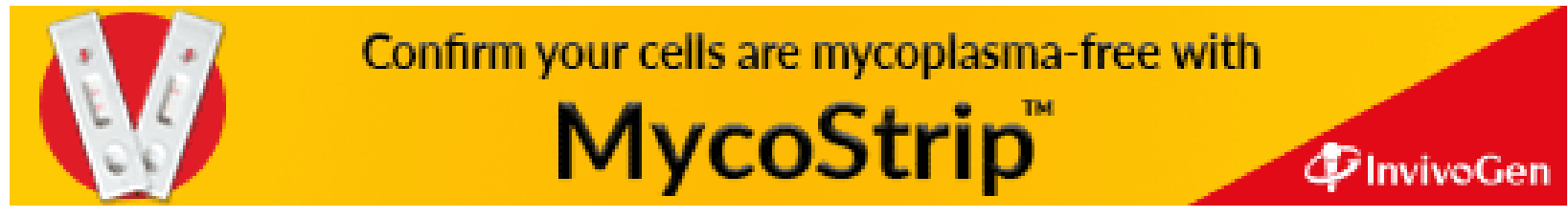

